\title{
Sedimentação coluvial pleistocênica na região de Presidente Figueiredo, nordeste do estado do Amazonas
}

\author{
Roseane Ribeiro Sarges ${ }^{1}$, Afonso César Rodrigues Nogueira ${ }^{2}$ \& Claudio Riccomini $^{3}$
}

\begin{abstract}
Resumo Depósitos coluviais pleistocênicos são descritos e datados na região de Presidente Figueiredo, Estado do Amazonas. O estudo sedimentológico-estratigráfico de afloramentos, integrado com análise geomorfológica e datação por luminescência opticamente estimulada, permitiu caracterizar a arquitetura e litofácies destas sucessões sedimentares e fornecer informações sobre a história da denudação e modificações da paisagem da Amazônia Central durante o Pleistoceno. Os depósitos coluviais consistem em areias e, principalmente, cascalhos com arcabouço aberto, matriz arenosa, acamamento maciço e, localmente, gradação inversa, sugestivos de deposição por fluxos gravitacionais e torrenciais, em condições de alta energia. Dois tipos de depósitos coluviais foram identificados: Depósito coluvial tipo 1, datado em 57.000 \pm 5.000 anos AP, que é composto por cascalhos e areias com fragmentos de pelito, crosta laterítica e arenito ferruginizado, recobrindo rochas do Eopaleozóico; e Depósito coluvial tipo 2,

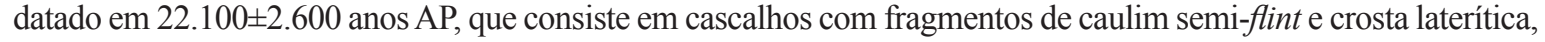
encontrado principalmente sobre os depósitos siliciclásticos caulínicos da Formação Alter do Chão, do CretáceoTerciário (?). A composição dos fragmentos indica como fontes as rochas fanerozóicas intemperizadas e os paleossolos lateríticos bauxítico-ferruginosos que foram removidos durante a denudação dos platôs. Os dois eventos de coluviação descritos aqui parecem confirmar que as fases principais de geomorfogênese seriam correlatas às duas fases climáticas secas e de recuo da floresta registradas para o final do Pleistoceno na Amazônia.
\end{abstract}

Palavras-chave: Depósitos coluviais, Pleistoceno, Amazônia central, datação por luminescência opticamente estimulada.

\begin{abstract}
Upper pleistocene colluvial sedimentation in the Presidente figueiredo region, northeastern state of Amazonas. This paper describe Upper Pleistocene colluvial deposits in the Presidente Figueiredo region, northestern State of Amazonas, Brazil. Outcrop-based sedimentologic and stratigraphic study, integrated with geomorphologic analysis and optically stimulated luminescence dating, allowed to characterize the architecture and lithofacies of these sedimentary successions and provided information about the denudation history and landscape changes in the central Amazonian region during the Pleistocene. The colluvial deposits consist of sands and mainly matrix-suppported gravels with massive beddding, locally with inverse grading, suggestive of deposition by gravitaty and torrential flows. Two types of colluvial deposits were identified: Colluvial deposits 1, dated at 57.000 \pm 5.000 years BP, constituted of gravels and sands with fragments of pelite, lateritic crusts and ferruginous sandstone, overlying Early Paleozoic rocks; and Colluvial deposits 2, yielding $22.100 \pm 2.600$ years BP, consisting of gravels with fragments of semi-flint kaolin and lateritic crust, overlying Cretaceous kaolinic silciclastic deposits of the Alter do Chão Formation. The types of fragments indicate as sources Phanerozoic weathered rocks and lateritic bauxitic and ferruginous laterites which were removed during denudation of plateau. The two colluvial events described here seem to confirm that the main phases of geomorphogenesis are correlated with periods of forest retreat related to the two dry climatic events recorded during the Upper Pleistocene in Amazonia.
\end{abstract}

Keywords: Colluvial deposits, sedimentary processes, central Amazonia, optically stimulated luminescence dating.

INTRODUÇÃO Depósitos quaternários são abundantes nas calhas dos grandes rios amazônicos, geralmente associados a terraços, barras e planícies de inundação. Por outro lado, depósitos desta idade desenvolvidos nas encostas dos platôs possuem baixo potencial de preservação, não só devido sua acumulação em espaço de acomodação reduzido, como também pelos processos morfogenéticos nas encostas. Além disso, a atuação do intenso intemperismo, comum na região amazônica, tende a homogeneizar esses depósitos com horizontes superiores de lateritas e solos desenvolvidos sobre unidades mais antigas (Horbe et al. 2001, Horbe

1 - Universidade de São Paulo, Instituto de Geociências, Programa de Pós-Graduação em Geoquímica e Geotectônica, São Paulo (SP), Brasil.

E-mail: rsarges@ufpa.br

2 - Universidade Federal do Pará, Faculdade de Geologia, Instituto de Geociências, Belém (PA), Brasil. Bolsista de produtividade em pesquisa do CNPq. E-mail: anogueira@ufpa.br

3 - Universidade de São Paulo, Instituto de Geociências, São Paulo (SP), Brasil. Bolsista de produtividade em pesquisa do CNPq.

E-mail: riccomin@usp.br 
\& Horbe 2005). Estes registros são caracterizados por fragmentos grossos, de tamanho seixo ou bloco, denominados linhas de pedra (stone lines, cf. Ruhe 1959) e camadas de pedra (stone layers, $c f$. Parizeck \& Woodruff 1957), que podem ter origem relacionada a paleopavimentos detríticos ou camadas coluviais (Ab'Saber 1967, Meis 1968 e 1971, Journaux 1975, entre outros), embora existam linhas de pedras na região formadas por processos geoquímicos (Horbe et al. 2001, Fritsch et al. 2002), conforme o modelo de Lecomte (1988).

A interpretação de uma dinâmica geomorfogenética com a formação de depósitos coluviais, relacionada aos processos de denudação e sedimentação na evolução da paisagem da região do Médio Amazonas, foi cogitada por Meis (1968 e 1971). Esta autora descreve paleopavimentos residuais detríticos e mantos coluviais, contendo fragmentos de crostas lateríticas desmanteladas, superpostos ao longo das vertentes. Atribui-se a formação destes depósitos a sucessivas fases de denudação, condicionadas à alternância de condições climáticas úmidas e secas. Esta interpretação, nas últimas décadas, tem sido preterida àquelas que envolvem um modelo básico de intemperismo e paisagem estática e constante, onde as linhas/camadas de pedra e solos que recobrem os perfis lateríticos seriam produtos formados "in situ" (Costa 1991, Horbe et al. 2001, Horbe \& Horbe 2005). Embora a existência de perfis lateríticos tenha impulsionado estudos na região, movidos principalmente pelo interesse econômico de descobertas dos depósitos de bauxita, a origem autóctone dos perfis lateríticos, por processos geoquímicos, foi também estendida para os solos e linhas/camadas de pedra, o que inibiu o reconhecimento de processos sedimentares relacionados à dinâmica de encosta. Processos de erosão e transporte foram indicados por Truckenbrodt \& Kotschoubey (1981), na Argila de Belterra, que recobre os perfis bauxíticos da Amazônia. Estes autores atribuem a ocorrência de fragmentos de diferentes tipos de gibbsita na argila, herdados das bauxitas erodidas, ao transporte por processos gravitacionais ou fluxo em lençol sob condições climáticas provavelmente áridas. Posteriormente, Koutschoubey \& Truckenbrodt (1999) associaram a origem de mantos coluviais à erosão de perfis lateríticos.

Neste trabalho resgata-se a interpretação geomorfogenética para os depósitos sedimentares que recobrem as encostas de platôs, esculpidas em unidades fanerozóicas da Bacia do Amazonas, particularmente na região de Presidente Figueiredo, Estado do Amazonas. As análises sedimentológica e geomorfológica, utilizadas neste trabalho, permitiram caracterizar as litofácies e a arquitetura deposicional dos depósitos coluviais. Adicionalmente, a datação por Luminescência Opticamente Estimulada (LOE) de dois tipos de depósitos coluviais mostrou idades pleistocênicas, correlacionáveis a eventos climáticos secos que contribuiram para a geração dos depósitos coluviais.

CONTEXTO GEOLÓGICO O substrato rochoso da região de Presidente Figueiredo (Fig. 1), borda norte da Bacia do Amazonas, compreende as formações paleozóicas Nhamundá, Pitinga e Manacapuru, do Grupo Trombetas, e rochas mesozóico-cenozóicas da
Formação Alter do Chão (Caputo et al. 1972, Caputo \& Sad inédito, Grahn 1991, Grahn \& Paris 1992, Melo inédito, Melo \& Steemans inédito, Cunha et al. 2004). A Formação Nhamundá é representada por quartzoarenitos e folhelhos glácio-marinhos de idade llandoveriana a wenlockiana (Nogueira et al. 1999, Soares et al. 2005). Folhelhos cinza-escuros intercalados com lentes de arenitos e de siltitos, que ocorrem nas margens do Rio Urubu, são posicionados no Ludlowiano a Lockhoviano (Coelho inédito) e relacionados à Formação Manacapuru. Os folhelhos encontrados imediatamente acima da Formação Nhamundá, no afloramento do km 108 da rodovia BR-174, tem sido considerados como pertencentes à Formação Pitinga de idade neolandoveriana a eoludloviana (Grahn 1991, Grahn \& Paris 1992, Nogueira et al. 1999).

Arenitos, siltitos e argilitos da Formação Alter do Chão recobrem discordantemente as unidades paleozóicas da região de Presidente Figueiredo, formando uma faixa contínua ao sul da área ou ocorrências isoladas (Figs. 1A e 1C), interpretadas como grábens (Souza \& Nogueira 2009). A Formação Alter do Chão foi posicionada no intervalo Aptiano-Cenomaniano por Dino et al. (1999) em subsuperfície, enquanto idade cenozóica (Eoceno?) foi sido admitida para o topo da unidade por Travassos \& Barbosa Filho (1990).

Perfis lateríticos estão desenvolvidos indistintamente sobre todas as unidades da região de Presidente Figueiredo e sustentam a maioria dos platôs. Crostas ferruginosas com horizonte bauxítico incipiente ou bem desenvolvido ocorrem em cotas mais elevadas ao norte e ao leste da área estudada, principalmente em unidades pré-cambrianas (Horbe et al. 2001, Peixoto \& Horbe 2008). Na área estudada, os horizontes de topo, caracterizados por crostas lateríticas e oxissolos, não foram observados, predominando apenas o horizonte mosqueado. Sedimentos argilosos intensamente caulinizados e, localmente, com aspecto semi-flint, ocorrem na porção superior da Formação Alter do Chão (Truckenbrodt et al. 1991, Kotschoubey et al. 1996 e 1997). Estes depósitos argilosos têm sido interpretados como produto de intemperismo de depósitos com volume significativo de grãos propícios à caulinização, como os feldspatos em areias arcosianas (Costa \& Moraes 1998, Giral-Kacmarcik et al. 1998). Os perfis lateríticos evidenciam fases de intemperismo que afetaram a Amazônia desde o Paleógeno (Truckenbrodt \& Kotschoubey 1981, Costa 1991, Fernandes Filho et al. 1997, Horbe et al. 2001). A fase de lateritização mais antiga remonta do Eoceno-Oligoceno até o Mioceno, enquanto que os perfis mais recentes provavelmente formaram-se no PlioPleistoceno (Costa 1990 e 1991, Horbe et al. 2001).

Atividades tectônicas cenozóicas estão amplamente registradas na área de estudo, principalmente por falhas normais e transcorrentes que truncam os perfis lateríticos e solos e, localmente, apresentam indícios de controle na sedimentação recente e feições geomorfológicas, tais como desembocaduras afogadas, capturas fluviais, cachoeiras e feições pseudocársticas, como relevos reliquiares e cavernas (Costa et al. 2001, Noguei- 


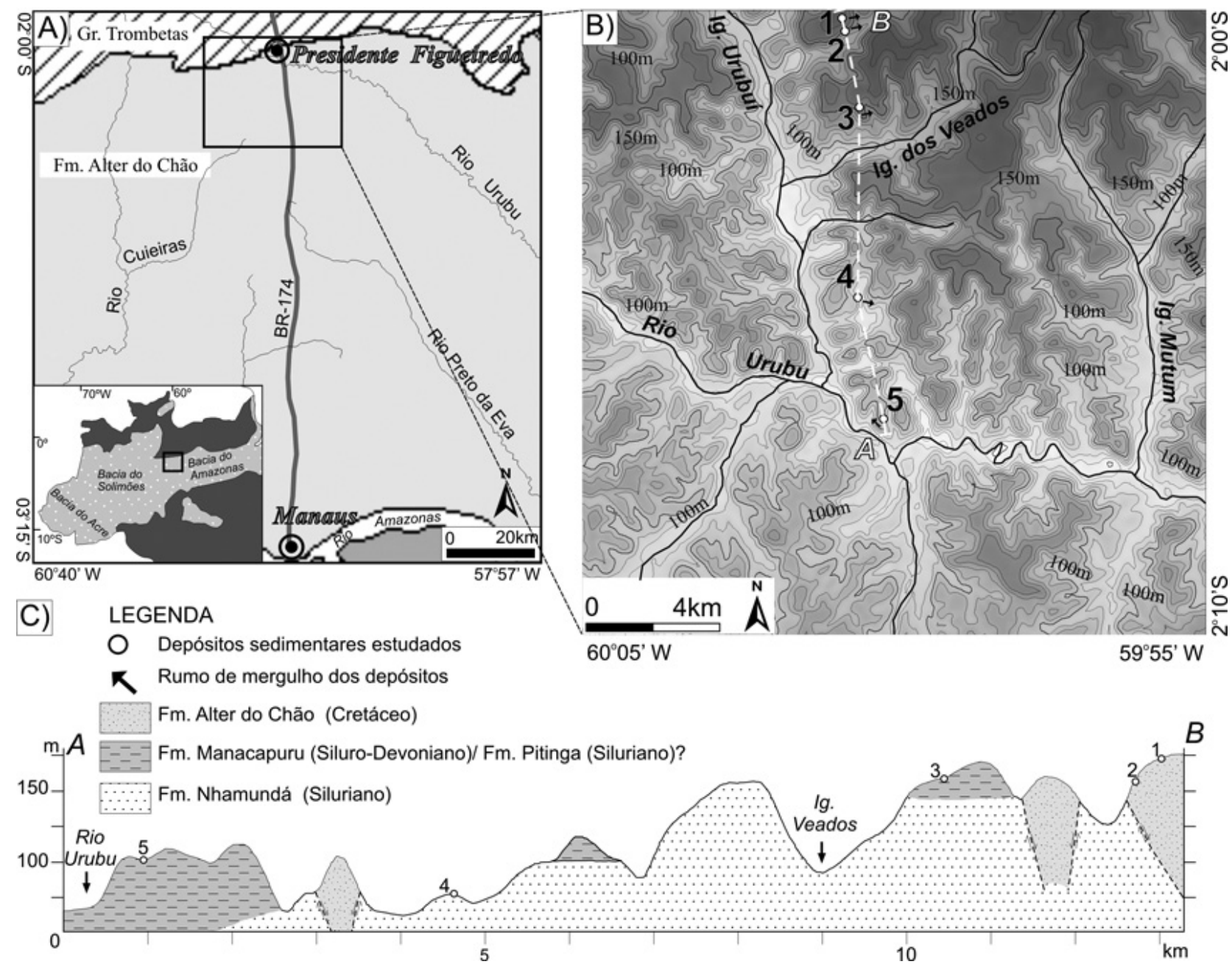

Figura 1 - Litoestratigrafia da região de Presidente Figueiredo, borda norte da Bacia do Amazonas, e localização dos afloramentos estudados (A). Platôs tabulares dissecados caracterizam a região com altimetria de até $150 \mathrm{~m}(\mathrm{~B})$. O nível de erosão aumenta em direção ao vale do Rio Urubu, e as unidades estratigráficas paleozóicas dispõem-se subhorizontalmente, sendo truncadas por estruturas tipo grábens preenchidas por depósitos cretáceos-terciários (C).

ra \& Sarges 2001, Franzinelli \& Igreja 2002).

MÉTODOS A caracterização dos depósitos de origem coluvial estudados envolveu análises estratigráfica e sedimentológica de afloramentos. Estes depósitos foram diferenciados com base na textura, composição e estruturas, na disposição topográfica e pelas relações de contato com as unidades paleozóicas e cretáceas-cenozóicas da Bacia do Amazonas. A descrição das fácies foi auxiliada pela confecção de seções panorâmicas de afloramentos em cortes de estradas (Fig. 1), para a melhor definição dos elementos arquiteturais e geometria, seguindo as recomendações de Walker (1992) e Arnot et al. (1997). Análises granulométricas foram realizadas em amostras selecionadas para complementar a caraterização textural das fácies. Modelos de fácies para depósitos coluviais ainda são escassos na literatura e, dessa forma, buscou-se utilizar a abordagem para sedimentos aluviais proposta por Miall (1992). As cores dos sedimentos foram classificadas de acordo com a carta de cores Munsell Rock Color Chart.
O mapa topográfico da área inserida entre as coordenadas geográficas 2000 'S e $60005^{\prime} \mathrm{W}$ a 2010 'S e 59055'W (Fig. 1), gerado a partir de Modelos Digitais de Elevação (MDE's) disponibilizados pelo USGS (2003), auxiliou na localização dos afloramentos e na análise da disposição dos depósitos em relação às vertentes. Foram realizadas datações de amostras de sedimentos dos locais 2 e 3 (Fig. 1B, 1C), pelo método da luminescência opticamente estimulada (LOE) com múltiplas alíquotas e regeneração total (MAR). As análises de LOE foram realizadas no laboratório LVD/ FATEC, em São Paulo, utilizando o equipamento Automated Systems, modelo 1100-series Daybreak Nuclear Instruments Inc, e a análise da dose anual efetuada como o equipamento Canberra Inspector Portable Spectroscopy Workstation (NaI - Tl).

DEPÓSITOS COLUVIAIS Os depósitos sedimentares estudados estão desenvolvidos no interflúvio dos igarapés Urubuí e Mutum, afluentes da margem direita 
do Rio Urubu, que compreende formas de relevo caracterizadas por platôs com baixa altimetria, com topos estreitos e alongados e cotas variando entre $70 \mathrm{~m}$ e 170m (Fig. 1B). Estes depósitos ocorrem nas vertentes caracterizados por segmentos convexos, em alguns casos quase retilíneos. De modo geral, são caracterizados por corpos sedimentares com geometria lenticular com extensão de até $30 \mathrm{~m}$ e com maior espessura de $3 \mathrm{~m}$. Corpos lenticulares, extensos por mais de uma dezena de metros e associados às encostas de platôs, e sedimentos geralmente grossos e ricos em matriz, com clastos provenientes das unidades e perfis lateríticos da região, corroboram com a interpretação de uma origem coluvial. Dois tipos de depósitos coluviais foram descritos para a região de Presidente Figueiredo: Depósitos coluviais tipo 1 (DC1) e Depósitos coluviais tipo 2 (DC2). Oxissolos argilo-arenosos ou areno-argilosos, de coloração amarelada ou alaranjada, que podem alcançar até $2 \mathrm{~m}$ de espessura, geralmente recobrem os depósitos coluviais.

Depósitos coluviais tipo 1 (DC1) - cascalhos e areias com fragmentos de pelito, crosta laterítica e arenito ferruginizado Os Depósitos coluviais tipo 1 (DC1) recobrem discordantemente unidades paleozóicas e mesozóico-cenozóicas ao longo de uma superfície in- clinada de até 5o, rumo aos vales da área. Os corpos coluviais apresentam geometria lenticular, com espessura máxima de $2 \mathrm{~m}$ (Figs. 2 e 3 ). Os fragmentos de folhelhos e arenitos do DC1 mostram-se parcialmente cimentados por óxido-hidróxidos de ferro (Fig. 2).

O DC1 é caracterizado por camadas de cascalhos que localmente alternam com camadas de areia, de espessura centimétrica (Fig. 3). As camadas de cascalhos possuem matriz arenosa a areno-argilosa, geralmente são maciços e apresentam clastos de tamanho seixo e matacão, muito angulosos, com baixa esfericidade e composição predominante de crosta ferruginosa. Grânulos de argilitos semi-flint de coloração branca acinzentada, fragmentos de gibbsita e seixos de ametista são raros nestes depósitos. Os fragmentos de crosta laterítica são geralmente muito angulosos e envoltos por película ferruginosa de coloração amarela, enquanto os seixos de argilitos são subarredondados e apresentam coloração arroxeada (cor 5P4/2). Nas camadas de cascalhos predomina o arcabouço aberto (fácies $\mathrm{Cma}$ ) sobre o fechado (fácies $\mathrm{Cmf}$ ), raramente ocorre gradação inversa (fácies Cgi) e a matriz arenosa apresenta coloração alaranjada (cor 10 YR 7/4). As camadas de areias finas a médias exibem acamamento maciço (fácies Am), coloração amarelada (cor 10 YR 6/6) e grânulos angulosos de quartzo disseminados (Fig. 3). As

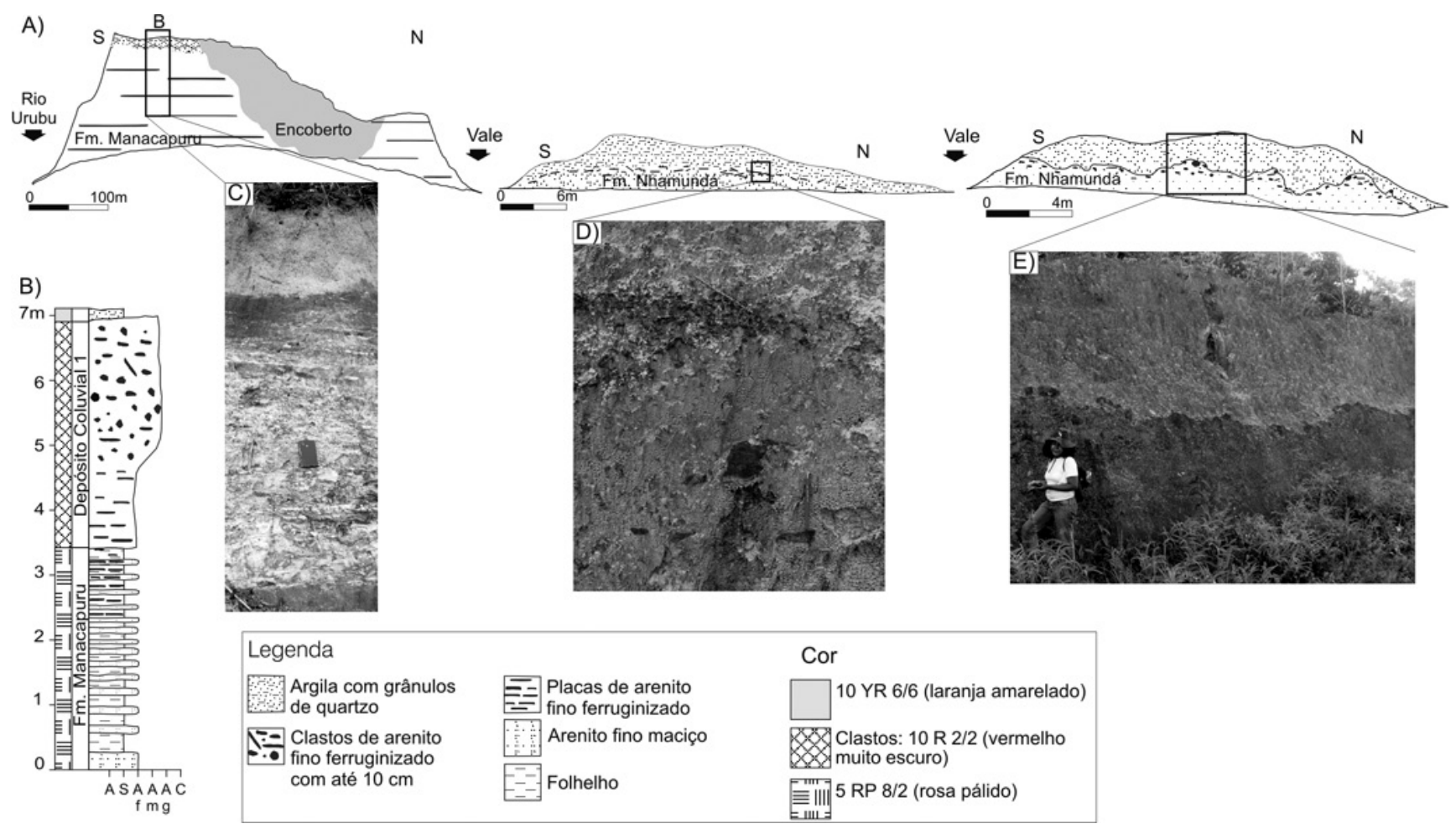

Figura 2 - Depósito coluvial tipo 1 (DC1), afloramento 5, margem esquerda do Rio Urubu. A) Seção geológica a partir do vale do Rio Urubu, onde o DC1 dispõe-se sobre as formações Manacapuru e Nhamundá. B) Perfil estratigráfico do DC1, exibindo granocrescência ascendente e gradação inversa. C) Detalhe dos arenitos ferruginizados devido à concentração de óxido-hidróxidos de ferro, que ocorrem no contato com a Formação Manacapuru. D e E) Detalhe dos depósitos coluviais com fragmentos dos arenitos ferruginizados da Formação Manacapuru. 


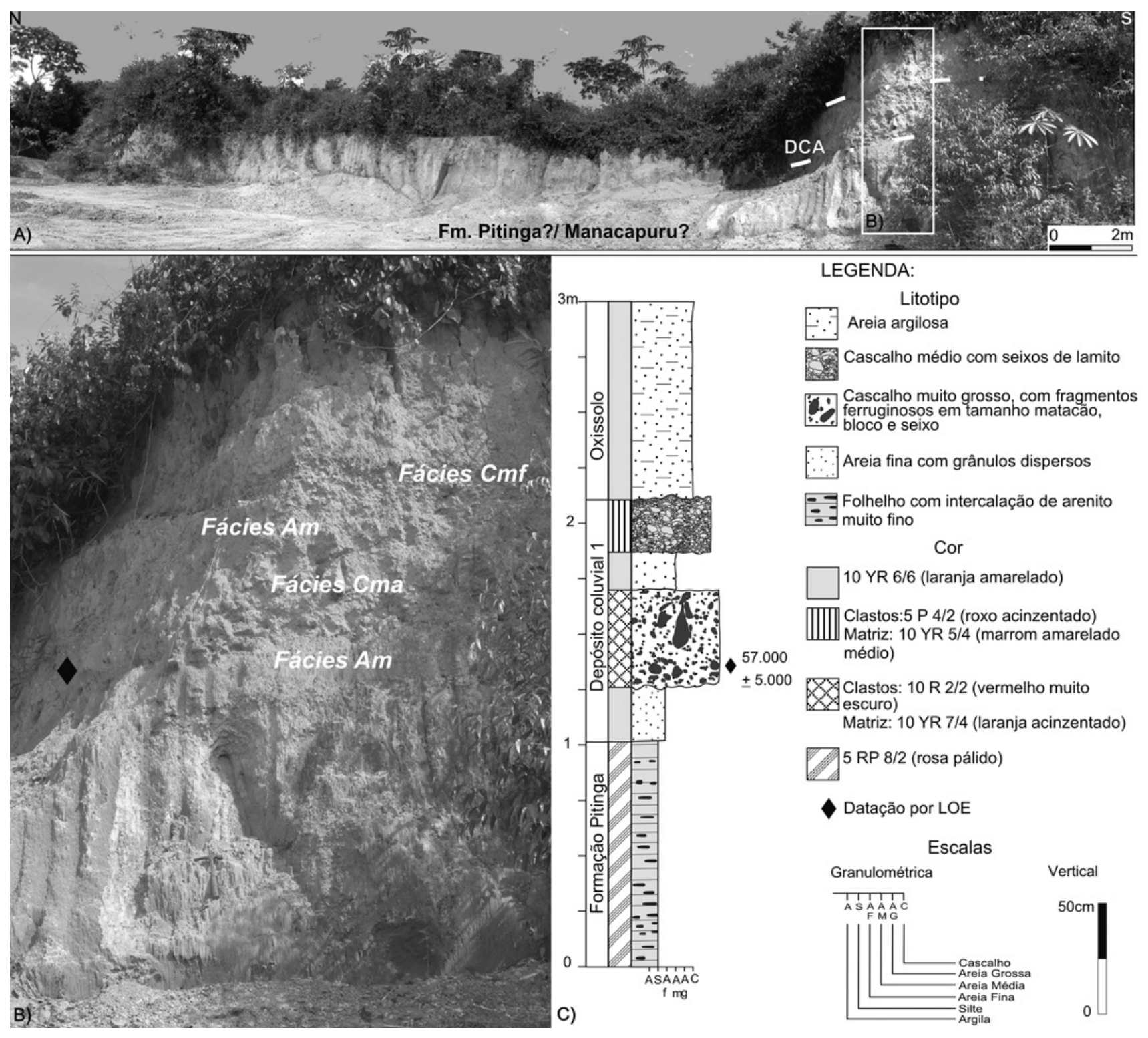

Figura 3 - Depósito coluvial tipo 1 (DC1), afloramento do km 108 da rodovia BR-174. A) Disposição do DCl na borda do platô, onde o depósito mergulha suavemente para a esquerda no rumo do vale de um dos afluentes do Igarapé dos Veados. B) O depósito se caracteriza por cascalho com arcabouço aberto (fácies Cma) e fechado (fácies Cmf) e areias maciças (fácies Am).

camadas de areia geralmente estão sobrepostas, em contato brusco, pelas camadas cascalhos, embora no perfil do Rio Urubu este contato seja transicional (Fig. 2).

\section{Depósitos coluviais tipo 2 (DC2) - cascalhos com fragmentos de argilitos semi-flint e crosta laterí- tica O Depósito coluvial tipo 2 (DC2) ocorre em contato brusco com a Formação Alter do Chão e foi depositado sobre uma superfície suavemente inclinada com até $3^{\circ}$ para sul (Fig. 4). É caracterizado por cama- das de cascalhos maciços, de arcabouço aberto e com fragmentos de argilito semi-flint de cor cinza (cor N8) (fácies $\mathrm{Cmsf}$ ), inseridos em matriz arenosa de colora- ção alaranjada (cor 10 YR 7/4). Os clastos, de tamanho}

seixo variam de 1 a 4cm, são mal-selecionados, sub-arredondados, com baixa esfericidade. Subordinadamente, ocorrem seixos com tamanho de até $1 \mathrm{~cm}$ de crosta laterítica e arenito ferruginizado, envoltos por película de cor castanho-amarelado. Lateralmente, a fácies Cmsf passa para cascalhos com fragmentos de crosta laterítica e areias maciças.

Processos deposicionais Os depósitos de cascalhos exibem predominantemente camadas maciças com arcabouço aberto (fácies Cma e Cmsf), constituídas por seixos, blocos e matacões em matriz arenosa a arenoargilosa, enquanto que gradação inversa (fácies Cgi) e arcabouço fechado (facies $\mathrm{Cmf}$ ) são subordinados. Os sedimentos foram depositados sob ação combinada de 
A)

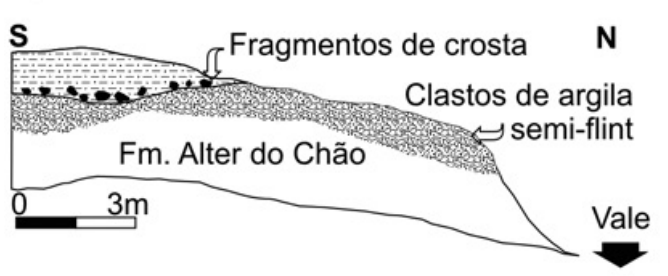

S

$\mathbf{N}$

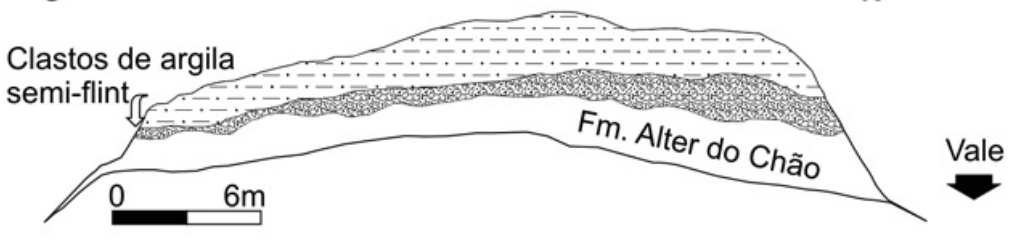

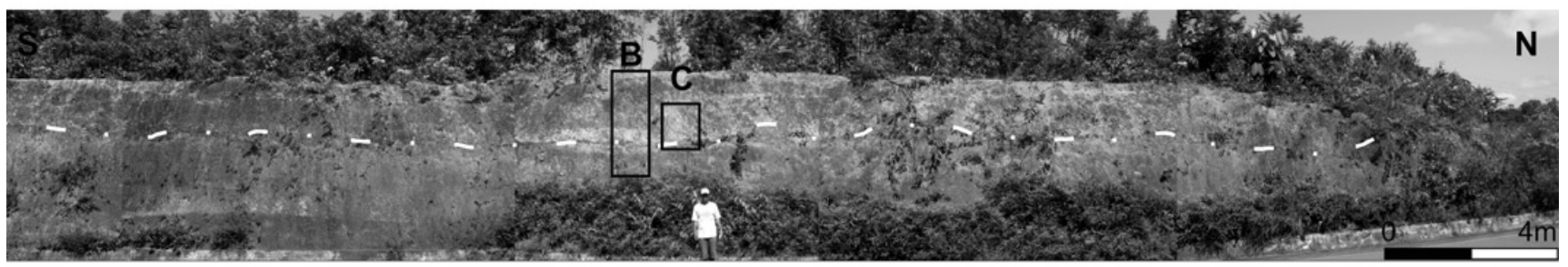

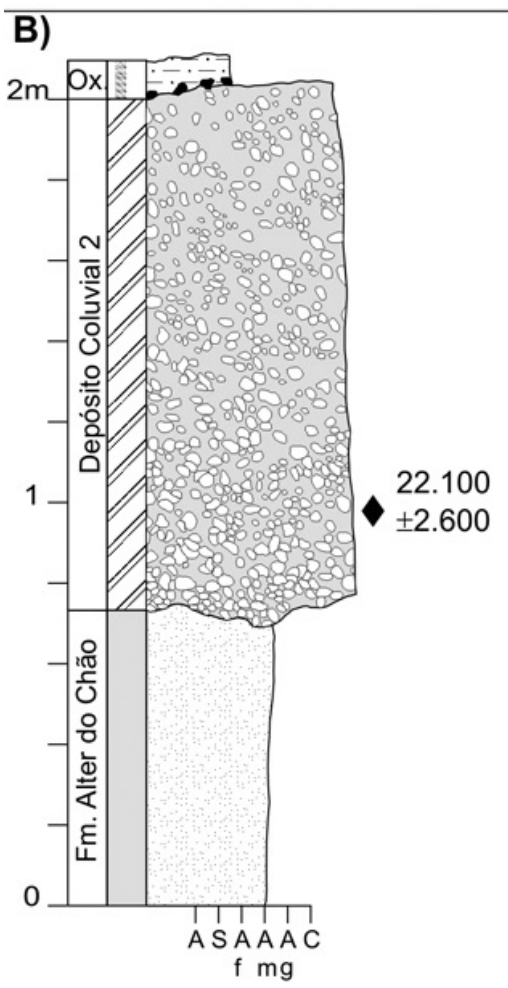

\section{LEGENDA:}
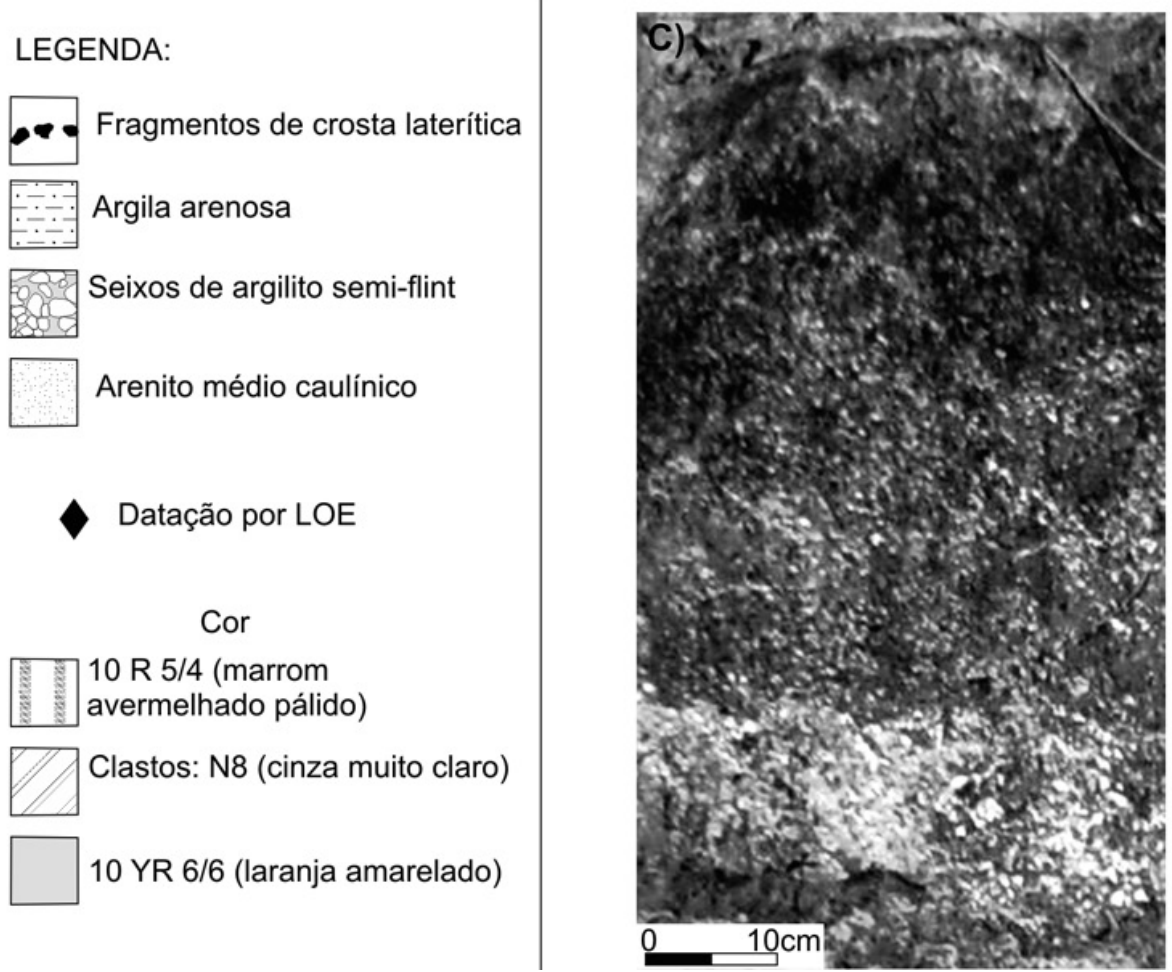

Figura 4 - Depósito coluvial tipo 2 (DC2), afloramento do km 110 da rodovia BR-174. A) Seção panorâmica com distribuiçãa do DC2. B) Perfil estratigráfico do DC2, apresentando cascalhos com arcabouço aberto. C) Detalhe do DC2, com clastos de caulim semi-flint.

processos gravitacionais, principalmente fluxo de detritos, e fluxos torrenciais e enxurradas. As fácies Cma e Cmsf indicam fluxo de detritos viscoso, enquanto a fácies Cmf, com arcabouço fechado, sugere fluxo menos viscoso, embora insuficiente para a geração de formas de leito. A pobre seleçãos dos clastos, desde grânulos a matacões, corrobora a alta viscosidade do fluxo, processo este também admitido para a fácies Am, já que estruturas hidrodinâmicas não foram observadas. A presença de gradação inversa (fácies Cgi) nos sedimentos grossos é indicativo de fluxos grãos de alta energia, caracterizadas por colisões grão-a-grão, onde as partículas mais finas passam pelas mais grossas. Cutículas ferruginosas sobre os clastos evidenciam a exposição e cimentação por óxido-hidróxido de ferro, sugestivos de exposição subaérea
(Truckenbrodt et al. 1991). Os depósitos compostos por diferentes fácies formadas em condições de diferentes viscosidades sugerem pulsos de coluviação. A composição dos clastos de crosta laterítica-bauxítica, quartzo, arenito ferruginizado e argilito semi-flint são indicativos da proveniência de paleossolos lateríticos ferruginosos e aluminosos, desenvolvidos sobre as unidades fanerozóicas aflorantes nos platôs da própria região, o que reforça a origem coluvial. Entretanto, não se descarta a erosão de pretéritas acumulações residuais, como paleopavimentos, e talvez até depósitos coluviais mais antigos.

Os oxissolos, que recobrem indiscriminadamente os depósitos coluviais, são de difícil interpretação por não apresentarem estruturas diagnósticas, somente superfícies que atestam escorregamento atual. 
As sucessões mais espessas destes oxissolos podem significar possíveis depósitos coluviais arenosos pedogenizados. Embora grande parte destes oxissolos seja interpretada como produto oriundo do intemperismo de crosta laterítica (Costa 1990 e 1991), a sua remobilização por processos de denudação do relevo, já citados por Horbe et al. (2001), parece ser mais provável e deve ter ocorrido em tempos muito recentes.

IDADE E EVENTOS CLIMÁTICOS Datações por termoluminescência têm sido usadas para posicionar cronologicamente os pulsos agradacionais de sedimentação coluvial e estabelecer sua possível correlação com as mudanças climáticas globais (Fuchs \& Lang 2009). Na região de Presidente Figueiredo, as datações por LOE nas areias maciças e matriz arenosa dos cascalhos forneceram idades de 57.000 \pm 5.000 anos AP, para o DC1 (Fig. 3), e 22.100 2.600 anos AP, para o DC2 (Fig. 4). Estas idades sugerem que pelo menos dois pulsos de coluviação tenham ocorrido no Pleistoceno Superior na região de Presidente Figueiredo.

Mudanças climáticas e paleohidrológicas durante o Pleistoceno e parte do Holoceno têm sido demonstradas em vários estudos desenvolvidos na região amazônica. Dados palinológicos em lagos "isolados" localizados em platôs na Serra de Carajás (sudeste da Amazônia), revelaram períodos mais secos no intervalo entre 60.000 e 45.000 anos AP e entre 23.000 e 11.000 anos AP, correspondendo às épocas de degradação e recuo da floresta amazônica (Turcq et al. 1993). Esta hipótese também foi considerada por Iriondo \& Latrubesse (1994) e Latrubesse (2002) para o período entre 65.000 a 25.000 anos AP da região do Médio Amazonas, ao obterem dados que indicaram este intervalo como de intensa atividade geomorfogenética dos canais fluviais, com maior variação anual de descarga e de cheia, e de ativa sedimentação aluvial, quando vigoravam condições climáticas mais áridas e menores taxas de precipitação anual. A ocorrência de prováveis geoformas eólicas descritas em Roraima (Latrubesse \& Nelson 2001, Carneiro et al. 2002, Teeuw \& Rhodes 2004) indicaria mudanças climáticas que poderiam ser as possíveis condicionantes de atividade geomorfogenética na região, com reativação de processos nas vertentes. As idades obtidas para a formação dos depósitos coluviais correspondem a fases climáticas mais secas, acompanhadas de recuo da vegetação, o que pode ter influenciado os processos geomorfogenéticos na região de Presidente Figueiredo no final do Pleistoceno.

\section{ORIGEM DOS COLÚVIOS E DISCUSSÕES FI-}

NAIS Depósitos coluviais têm sido pouco discutidos nos trabalhos da região Amazônica. Os primeiros trabalhos que trataram os depósitos coluviais usaram um modelo básico isostático entre períodos glaciais e interglaciais. Atualmente este modelo não pode ser aplicado devido, principalmente, às grandes oscilações climáticas e do nível do mar estarem relacionas a um mesmo ciclo glacial, e a impossibilidade de aplicar um modelo de transmissão de mudança de nível de base à montante de grandes rios ao longo de grandes extensões, como é o caso da Amazônia. Enquanto as variações eustáticas controlam o padrão estratal das sequências deposicionais de ambientes marinhos, no caso dos ambientes deposicionais continentais os controles climáticos e/ ou tectônicos são predominantes (Shanley \& McCabe 1994). As fases de denudação, que dependem das mudanças do nível de base regional, são geralmente associadas a alterações climáticas e/ou atividades tectônicas. A erosão das vertentes durante períodos de mudança paleoclimática, com redução da cobertura vegetal, é um modelo com maior aplicação em escalas milenares do que em intervalos glaciais-interglaciais de longa duração.

Os processos denudacionais que prevaleceram no Pleistoceno Superior geraram depósitos coluviais e aluviais sobre toda a bacia hidrográfica Amazônica. Neste contexto, os depósitos coluviais DC1 e DC2, formados principalmente por fluxos gravitacionais, consistem nos mais importantes registros estratigráficos desta idade até agora reconhecidos na região de Presidente Figueiredo. Apesar dos depósitos apresentarem composição diversificada, em função de suas proveniências a partir de diferentes rochas aflorantes em uma área de poucas dezenas de quilômetros quadrados da borda noroeste da Bacia do Amazonas, os DC1 e DC2 são considerados homogêneos. Esta homogeneidade parece indicar longos períodos de estabilidade da paisagem, suficiente para o desenvolvimento de espessas coberturas de solos posteriormente envolvidos na dinâmica das vertentes.

As idades de $57.000 \pm 5.000$ anos AP (DC1) e $22.100 \pm 2.600$ anos AP (DC2) são correlatas aos dois períodos mais secos que ocorreram na Amazônia, entre 60.000 e 45.000 anos AP e entre 23.000 e 11.000 anos AP, com denudação e recuo de florestas (Fig. 5). De fato, o início de uma fase climática árida, que pode estar relacionada a uma fase glacial ou condições climáticas mais frias, pode ter causado a redução da cobertura vegetal nos platôs e vales da região de Presidente Figueiredo, com a exposição dos solos e paleossolos lateríticos e o aumento de sua vulnerabilidade à erosão, favorecendo o rápido retrabalhamento dos sedimentos nas vertentes dos platôs, durante a transição climática, conforme o modelo de Wells et al. (1987) e Bull (1991). Este estudo, tentativamente, sugere um possível sincronismo entre os depósitos coluviais da região de Presidente Figueiredo e o acúmulo de sedimentos gerados durante transições climáticas de escala milenar, coadunado pelas datações obtidas no DC1 e DC2. Os intervalos de tempo também podem ser tentativamente comparados às variações climáticas ligadas ao Pleniglacial médio a superior da glaciação Wisconsin (Latrubesse 2002).

A influência da neotectônica na sedimentação coluvial na Amazônia é um assunto ainda em discussão. É notório na região amazônica o registro de falhas e fraturas que, em parte, exercem controle no sistema fluvial (Sternberg 1950, Wanderley Filho 1991, Fernandes Filho et al. 1997, Costa et al. 2001, Nogueira \& Sarges 2001, Franzinelli \& Igreja 2002, Latrubesse \& Franzi- 

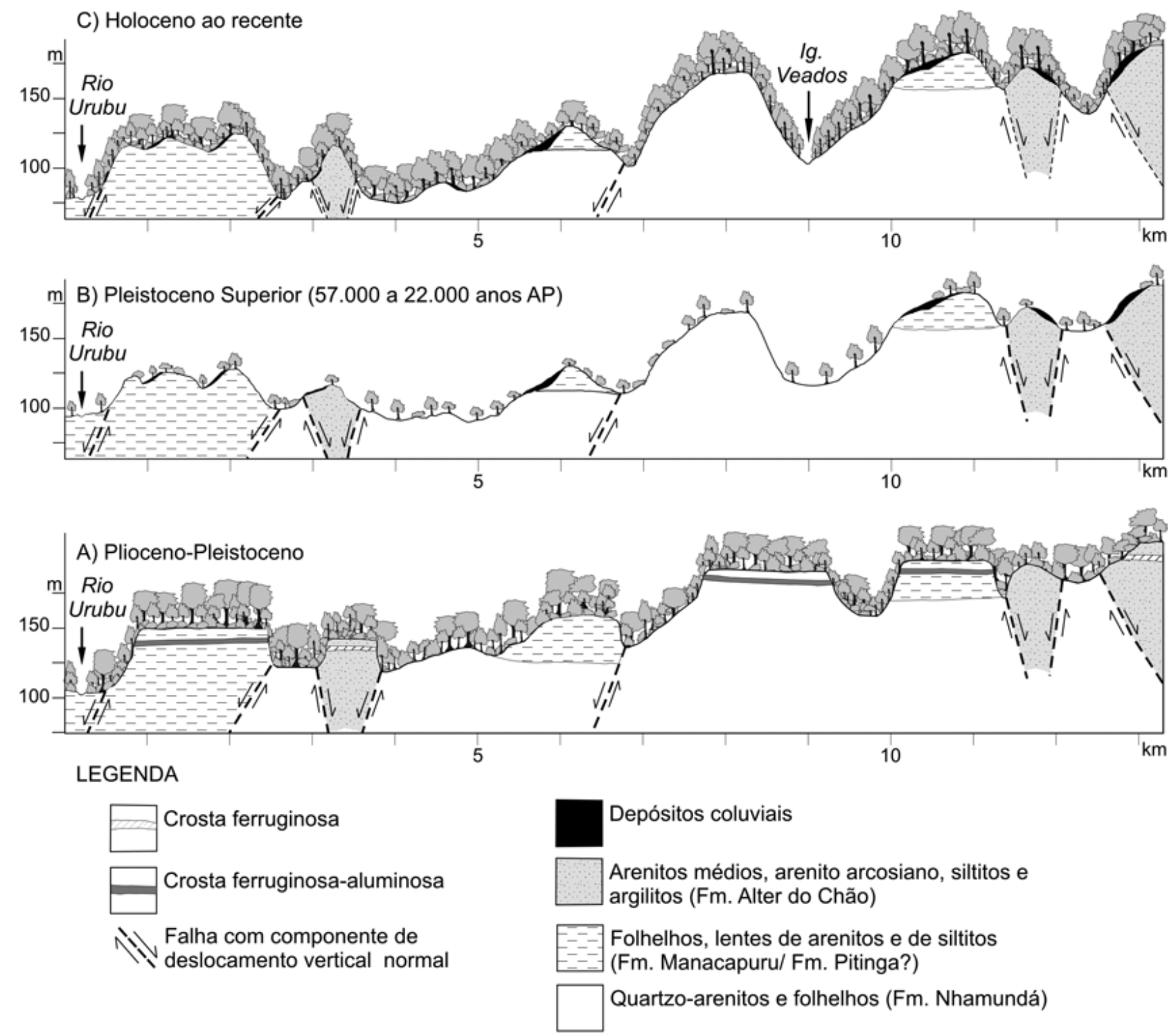

Figura 5 - Proposta evolutiva para os eventos de coluviação e o modelamento do relevo da região de Presidente Figueiredo. A) Plio-Pleistoceno: unidades eopaleozóicas e cretáceas-cenozóicas afetadas por falhas, após o desenvolvimento dos perfis lateríticos ferruginosos, formam um arranjo de grábens e horsts, com a intensa caulinização sobre as rochas arcosianas. Condições de clima úmido favorecem a implantação de uma densa cobertura vegetal sobre platôs pouco dissecados, sustentados por perfis lateríticos. B) Pleistoceno Superior (57.000 a 22.000 anos AP): começam a vigorar condições de clima árido, que causam a redução da cobertura vegetal nos platôs e vales e intensificam os processos de dinâmica de vertentes. Os solos e paleossolos lateríticos expostos, juntamente com as rochas intemperizadas, deram origem aos colúvios dos depósitos tipo 1 (DC1) e depósitos tipo 2 (DC2). C) Holoceno ao Recente: retorno das condições de clima úmido, com desenvolvimento de densa cobertura vegetal.

nelli 2002, entre outros). Contudo, a influência desta tectônica parece ser mínima na formação dos depósitos coluviais. Embora sejam observadas falhas que truncam perfis lateríticos e rochas na região de Presidente Figueiredo (Nogueira \& Sarges 2001, Silva 2005), não é nítido se estas contribuíram para as condições regionais de morfogênese e na reativação de vertentes. Existe um descompasso de tempo entre a geração dos colúvios depositados episodicamente e a elevação de blocos tectônicos por epirogênese, que pode levar milhões de anos. É provável que a atividade neotectônica possa ter causa- do soerguimentos e contribuído para os suprimentos de sedimentos, sobretudo nos ultimos milhões de anos. Entretanto, é possível que a escala de observação utilizada neste trabalho não permita constatar essa influência. Da mesma forma, faltam evidências para atrelar a deposição dos sedimentos coluviais a possíveis atividades sísmicas. De fato, colúvios são produzidos em uma ampla diversidade de ambientes, independentemente de serem tectonicamente ativos ou não, mas em função do grau de estabilidade das vertentes.

Admite-se que as mudanças climáticas que afe- 
taram a Amazônia durante o Pleistoceno tenham sido os fatores preponderantes na reativação das vertentes e responsáveis pelos processos coluviais registrados na região de Presidente Figueiredo. Assim, alteração das condições climáticas e da cobertura vegetal pode ser usada para justificar a ocorrência de diversos eventos de coluviação, embora não se descarte que breves e intensos períodos de precipitação pluvial, durante a transição paleoclimática, possam ter contribuído na deposição dos DC1 e DC2. É necessário estender este estudo para outras áreas para confirmar a acumulação constante de sedimentos em vertentes durante o Quaternário. É possível que a combinação das mudanças paleoclimáticas e, subordinadamente, atividades neotectônicas, tenham influenciando na mudança do nível de base local da região de Presidente Figueiredo, com consequente reconfiguração do relevo.

Agradecimentos À FAPESP pelo suporte financeiro neste trabalho e pela concessão de bolsa DR a Roseane Ribeiro Sarges (Processo 02/09564-0) e à Gerência de Hidrologia da CPRM-Sureg AM, pelo apoio logístico e infra-estrutura disponibilizada nos levantamentos de campo. Os agradecimentos são extensivos ao Prof. Dr. Werner Truckenbrodt, Prof. Dr. Claudio Limeira Mello e ao revisor anônimo, pelas valiosas críticas e sugestões.

\section{Referências}

Ab’Saber A.N. 1967. Problemas Geomorfológicos da Amazônia Brasileira. In: Simpósio sobre a Biota Amazônica, Rio de Janeiro, atas, 1:35-67.

Arnot M.J., Good T.R., Lewis J.J.M. 1997. Photogeological and image-analysis techniques for collection of largescale outcrop data. J. Sediment. Res., 67:984-987.

Bull W.B. 1991. Geomorphic Responses to Climatic Change. New York, Oxford Press, 326p.

Caputo M.V., Rodrigues R., Vasconcelos D.N.N. 1972. Nomenclatura estratigráfica da Bacia do Amazonas Histórico e atualização. In: SBG, Cong. Bras. Geol., 26, Resumos, 3:35-46.

Carneiro Filho A., Schwartz D., Tatumi S.H., Rosique T. 2002. Amazonian paleodunes provide evidence for drier climate phases during the Late Pleistocene-Holocene. Quaternary Research, 58:205-209.

Costa M.L. \& Moraes E.L. 1998. Mineralogy, geochemistry and genesis of kaolins from the Amazon region. Miner. Depos. 33:3-297.

Costa J.B.S., Bemerguy R.L., Hasui Y., Borges M.S. 2001. Tectonics palaeogeography along the Amazon river. J. S. Am. Earth Sciences, 14:335-347.

Costa M.L. 1990. Potencial metalogenético dos lateritos da Amazônia. In: Cong. Bras. Geol., 36, 3:1371-1385.

Costa M.L. 1991. Aspectos geológicos dos lateritos da Amazônia. Rev. Bras. Geoc., 21:146-160.

Cunha P.R.C., Gonzaga F.G., Coutinho L.F.C., Feijó F.J. 1994. Bacia do Amazonas. Bol. de Geoc. PETROBRÁS, 8(1):47-55.

Dino R., Silva O.B., Abrahão D. 1999. Caracterização palinológica e estratigráfica de estratos cretáceos da Formação Alter do Chão, Bacia do Amazonas. In: Simp. Cretáceo do Brasil, 5, Bol. Resumos, p. 557-565.

Fernandes Filho L.A., Costa M.L., Costa J.B.S. 1997. Registros neotectônicos nos lateritos de ManausAmazonas. Geociências, 16:9-33.

Franzinelli E. \& Igreja H.L.S. 2002. Modern sedimentation in the Lower Negro River, Amazonas State, Brazil. Geomorphology, 44:259-271.

Fritsch E., Montes-Lauar C.R., Melfi A.J., Balan E., Magat P. 2002. Lateritic and redoximhorphic features in a faulted landscape near Manaus, Brazil. European Journal of Soil Science, 53:203-217.
Fuchs M. \& Lang A. 2009. Luminescence dating of hillslope deposits - a review. Geomorphology, 109:17-26.

Giral-Kacmarcik S., Nahon D.B., Girard J.P., Lucas Y., Abel L.J. 1998. Oxigene isotope geochemistry of kaolinite in laterite-forming processes, Manaus, Amazonas, Brazil. Geochimica et Cosmochimica Acta, 62:1865-1879.

Grahn Y. 1991. Ordovician chitinozoa and biostratigraphy of Brazil. Geobios, 25(6):703-723.

Grahn Y \& Paris F. 1992. Age and correlation of the Trombetas Group, Amazonas Basin, Brazil. Rev. Micropal., 35(3):197-209.

Horbe A.M.C. \& Horbe M.A. 2005. Linhas de pedra na região nordeste do Amazonas. In: Horbe A.M.C. \& Souza V.S. (Org.) Contribuições à Geologia da Amazônia. Manaus, Sociedade Brasileira de Geologia, 4:221-229.

Horbe A.M.C., Nogueira A.C.R., Horbe M.A., Costa M.L., Suguio K. 2001. A lateritização na gênese das superfícies de aplanamento da região de Presidente FigueiredoBalbina, nordeste do Amazonas. In: Reis J. \& Monteiro M.A.S. (coord.) Contribuições à Geologia da Amazônia. Manaus, Sociedade Brasileira de Geologia, 2:148-176.

Iriondo M. \& Latrubesse E. M. 1994. A probable scenario for a dry climate in central Amazonia during the late Quaternary. Quaternary International, 21:121-128.

Journaux M.A. 1975. Gemorphologie des bordures de L'Amazonie Bresilienne: le modele versants: essai d'evolution paléoclimatique. Bulletin Association Geographie de La France, 422/423:5-19.

Kotschoubey B., Truckenbrodt W., Hieronymus B. 1996. Depósitos de caulim e argila semi-flint no nordeste do Pará. Rev. Bras. Geoci., 26:71-80.

Kotschoubey B., Truckenbrodt W. Hieronymus B. 1997. Bauxite deposits of Paragominas. In: Carvalho A., Boulangé B., Melfi A.J., Lucas Y. (eds.) Brazilian Bauxites. São Paulo, FAPESP/ORSTOM, p. 75-106.

Kotschoubey B. \& Truckenbrodt W. 1981. Evolução poligenética das bauxitas do distrito de ParagominasAçailândia (Estados do Pará e Maranhão). Rev. Bras. Geoc., 11:193-202.

Latrubesse E.M. \& Franzinelli E. 1998. Late Quaternary Alluvial Sedimentation in the Upper Rio Negro Basin, Amazonia, Brazil: Paleoclimatic Implications. In: Benito G., Gregory K., Baker V. (org.) Paleohydrology 
and Environmental Change. John Wiley \& Sons Ltd, p. 259-271.

Latrubesse E.M. \& Franzinelli E. 2005. The late Quaternary evolution of the Negro River, Amazon, Brazil: implications for island and floodplain formation in large anabranching tropical systems. Geomorphology, 70(34):372-397.

Latrubesse E.M. \& Nelson B.W. 2001. Evidence for Late Quaternary aeolian activity in the Roraima-Guyana Region. Catena, 43:63-80.

Latrubesse E.M. \& Franzinelli E. 2002. The Holocene alluvial plain of the midle Amazon River, Brazil. Geomorphology, 44:241-257.

Latrubesse E.M. 2002. Evidence of quaternary palaeohydrological changes in middle Amazonia: The Aripuanã-Roosevelt and Jiparaná fans. Zeitschrift für Geomorphologie NF, 129(1):41-59.

Lecomte P. 1988. Stone lines profiles: importance in geochemical exploration. J. Geochem. Explor., 30:3561.

Leopold M. \& Völkel J. 2007. Colluvium: Definition, differentiation, and possible suitability for reconstructing Holocene climate data. Quaternary International, 162/163:133-140.

Meis M.R.M. 1968. Considerações sobre o Médio Amazonas. Rev. Bras. Geogr., 30(2):3-20.

Meis M.R.M. 1971. Upper Quaternary process of the middle Amazon area. GSA Bull., 82:1073-1078.

Miall A.D. 1992. Alluvial Deposits. In: Walker R.G. \& James N.P. (eds.) Facies Models - Response to Sea Level Change. Geological Association of Canada, Geotext1, p. 119-142.

Nogueira A.C.R. \& Sarges R.R. 2001. Characterization and genesis of waterfalls of the Presidente Figueiredo region, Northeast State of Amazonas, Brazil. An. Acad. Bras. Ciênc., 73:287-301.

Nogueira A.C.R., Truckenbrodt W., Soares E.A.A. 1999. O icnogênero Arthrophycus de depósitos sublitorâneos da Formação Nhamundá (Siluriano Inferior) da Bacia do Amazonas, região de Presidente Figueiredo. Rev. Bras. Geoc., 29(2):135-140.

Parizek E.J. \& Woodruff J.F. 1957. Description and origin of stone layers in soils of the southeastern states. $J$. Geology, 65:24-34.

Peixoto S.F. \& Horbe A.M.C. 2008. Bauxitas do nordeste do Amazonas. Rev. Bras. Geoc., 38(2):406-422.

Ruhe R.V. 1959. Stone lines in soils. Soil Science, 84:223231.

Shanley K.W. \& McCabe P.J. 1994. Perspectives on the sequence stratigraphy of continental strata. A.A.P.G.
Bulletin, 78:544-568.

Silva C.L. 2005. Análise tectônica cenozóica da região de Manaus e adjacências. Tese de Doutoramento, Instituto de Geociências e Ciências Exatas, UNESP, 278p.

Soares E.A.A., Truckenbrodt W., Nogueira A.C.R. 2005. Fácies Litorâneas e Subglaciais da Formação Nhamundá (Siluriano Inferior), Região de Presidente Figueiredo, Bacia do Amazonas. Rev. Museu Paraense Emílio Goeldi, 1(2):89-116.

Souza V. \& Nogueira A.C.R. 2009. Seção Geológica Manaus Presidente Figueiredo (AM), Borda Norte da Bacia do Amazonas: Um Guia Para Excursão de Campo. Rev. Bras. Geoc., 39(1):16-29.

Sternberg H.O. 1950. Vales tectônicos na planície amazônica? Rev. Bras. Geogr., 12:3-26.

Teeuw M.R. \& Rhodes E.J. 2004. Aeolian activity in northern Amazonia: optical dating of Late Pleistocene and Holocene palaeodunes. Journal of Quaternary Science, 19(1):49-54.

Travassos W.A.S. \& Barbosa Filho C.M. 1990. Tectonismo Terciário na área do rio Tapajós, Bacia do Amazonas. Bol. Geoc. PETROBRÁS, 4(3):221-340.

Truckenbrodt W. \& Kotschoubey B. 1981. Argila de Belterra - cobertura terciária das bauxitas amazônicas. Rev. Bras. Geoc., 11:203-208.

Truckenbrodt W., Kotschoubey B., Schellmann W. 1991. Composition and origin of the clay cover on North Brazilian laterites. Geol. Rundsch., 80:591-610.

Turcq B., Suguio K., Martin L., Flexor J.M. 1993. Registros milenares nos sedimentos dos lagos da Serra dos Carajás. Ciência Hoje, 16:31-35.

USGS. 2003. Global DEM 3”. Disponível em http:// seamless.usgs.gov. Acessado em setembro de 2003.

Walker R.G. 1992. Facies, facies models and modern stratigrahic concepts. In: Walker R.G. \& James N.P. (eds.) Facies Models - Response to Sea Level Change. Geological Association of Canada, Geotext1, p. 1-14.

Wanderley Filho J.R. 1991. Evolução estrutural da bacia do Amazonas e sua relação com o embasamento. Dissertação de Mestrado, Centro de Geociências, UFPA, $125 \mathrm{p}$.

Wells S.G., McFadden L.D., Dohrenwend J.C. 1987. Influence of late Quaternary climatic changes on geomorphic and pedogenic processes on a desert piedmont, eastern Mojave Desert, California. Quaternary Research, 27:130-146.

Manuscrito ID 9958

Submetido em 12 de dezembro de 2007 Aceito em 24 de junho de 2009 